\title{
Randomized Trial
}

\section{Lumbar Facet Joint Nerve Blocks in Managing Chronic Facet Joint Pain: One-Year Follow-up of a Randomized, Double-Blind Controlled Trial: Clinical Trial NCT00355914}

Laxmaiah Manchikanti, MD¹, Vijay Singh, MD², Frank J.E. Falco, MD³, Kimberly A. Cash, RT ${ }^{1}$, and Vidyasagar Pampati, MSc ${ }^{1}$

From: ${ }^{1}$ Pain Management Center of Paducah, Paducah, KY; ${ }^{2}$ Pain Diagnostic Associates, Niagara, WI; and ${ }^{3}$ Mid Atlantic Spine \& Pain Specialists of Newark, DE.

Dr. Manchikanti is Medical Director of the Pain Management Center of Paducah, Paducah, KY, and Associate

Clinical Professor of Anesthesiology and Perioperative Medicine,

University of Louisville, Louisville, KY.

Dr. Singh is Medical Director, Pain

Diagnostic Associates, Niagara, WI.

${ }^{3}$ Dr. Falco is Clinical Assistant Professor, Temple University Medical School, Philadelphia, PA, and Medical Director of the Mid Atlantic Spine \&

Pain Specialists, Newark, DE. Ms. Cash is a Research Coordinator at the Pain Management Center of Paducah, Paducah, KY.

Mr. Pampati is a Statistician at the Pain Management Center of Paducah, Paducah, KY.

Address correspondence: Laxmaiah Manchikanti, M.D. 2831 Lone Oak Road

Paducah, Kentucky 42003 E-mail: drlm@thepainmd.com

Disclaimer: There was no external funding in the preparation of this manuscript.

Conflict of interest: None.

Manuscript received: $12 / 21 / 2007$

Revised manuscript received: 01/28/2008

Accepted for publication: $02 / 15 / 2008$

Free full manuscript: www.painphysicianjournal.com
Background: Lumbar facet joints have been implicated as the source of chronic pain in $15 \%$ to $45 \%$ of patients with chronic low back pain. Various therapeutic techniques including intraarticular injections, medial branch blocks, and radiofrequency neurotomy of lumbar facet joint nerves have been described in the alleviation of chronic low back pain of facet joint origin.

Objective: The study was conducted to determine the clinical effectiveness of therapeutic local anesthetic lumbar facet joint nerve blocks with or without steroid in managing chronic function-limiting low back pain of facet joint origin.

Design: A randomized, double-blind, controlled trial.

Setting: An interventional pain management setting in the United States.

Methods: This study included 60 patients in Group I with local anesthetic and 60 patients in Group II with local anesthetic and steroid. The inclusion criteria was based on the positive response to the diagnostic controlled comparative local anesthetic lumbar facet joint blocks.

Outcome measures: Numeric pain scores, Oswestry Disability Index, opioid intake, and work status. All outcome assessments were performed at baseline, 3 months, 6 months, and 12 months.

Results: Significant improvement with significant pain relief (> 50\%) and functional improvement (> 40\%) were observed in $82 \%$ and $85 \%$ in Group I, with significant pain relief in over $82 \%$ of the patients and improvement in functional status in $78 \%$ of the patients.

Based on the results of the present study, it appears that patients may experience significant pain relief 44 to 45 weeks of 1 year, requiring approximately 3 to 4 treatments with an average relief of 15 weeks per episode of treatment.

Conclusion: Therapeutic lumbar facet joint nerve blocks, with or without steroid, may provide a management option for chronic function-limiting low back pain of facet joint origin.

Key words: Chronic low back pain, lumbar facet or zygapophysial joint pain, facet joint nerve or medial branch blocks, comparative controlled local anesthetic blocks, therapeutic lumbar facet joint nerve blocks

Pain Physician 2008; 11:121-132 
umbar intervertebral discs, facet joints, and sacroiliac joints are the major sources of painful conditions originating from lumbosacral pain with pain in the low back and/or lower extremities. Lumbar facet joints have been implicated as the source of chronic pain in $15 \%$ to $45 \%$ of patients with chronic low back pain (1-8), based on the responses to controlled diagnostic blocks, in accordance with the criteria established by the International Association for the Study of Pain (9). Further, facet joints of the lumbar spine have been shown to be capable of causing pain in the low back with referred pain to the lower extremity in normal volunteers (10-20), have been shown to be a source of pain in patients with chronic low back pain using diagnostic techniques of known reliability and validity $(1-8,12-15)$, and neuroanatomic and physiologic studies have shown that lumbar facet joints have abundant nerve supply and nociceptors (21). Finally biochemical studies also have confirmed the contribution of the facets to load transmission in the spine and have indicated the possibility of facet overload resulting in stiffness, or rigidity, through prolonged immobilization, even without degenerative or other pathologic findings on diagnostic imaging $(22,23)$. A condition termed segmental rigidity also has been described with the mobility deficits affecting the 3-joint complex that involves the articulation between 2 vertebrae consisting of the intervertebral disc and adjacent facet joints at one or more lumbar levels (24).

Multiple therapeutic techniques have been described and established in managing chronic low back pain of facet joint origin, though controversial (25-30). Intraarticular lumbar facet joint injections $(31,32)$, lumbar facet joint nerve blocks $(33,34)$, and radiofrequency neurotomy $(35,36)$ all have been shown to be moderately effective. However, there is a paucity of evidence based on randomized controlled trials. Lumbar facet joint nerve blocks are considered an alternative to percutaneous radiofrequency neurotomy. Radiofrequency neurotomy of lumbar facet joint nerves provides temporary or long-term relief of pain by denaturing the nerves that innervate the painful joint. Consequently, pain returns when the axons regenerate, with reinstatement of pain relief possible with repeating the procedure, whereas, with lumbar facet joint nerve blocks, the exact phenomenon of therapeutic effect is not well known. Lumbar facet joint nerve blocks may be repeated to reinstate the relief without any deleterious effects. Intraarticular injections are based on the philosophy that there is inflammation.
In this study, we sought to evaluate the effectiveness of lumbar facet joint nerve blocks in providing relief for chronic, function-limiting low back pain in a randomized, double-blind, controlled evaluation, in patients with chronic low back pain of facet joint origin. This is a report of the one-year follow-up of 120 patients from a study scheduled for a 2-year follow-up.

\section{Methods}

The study was conducted in an interventional pain management practice, a specialty referral center, in a private practice setting in the United States. The study was performed based on CONSORT guidelines (37). The study protocol was approved by the Institutional Review Board and registered on U.S Clinical Trial Registry with an assigned number of NCT00355914.

\section{Participants}

Patients were assigned to 1 of 2 groups with Group I patients receiving lumbar facet joint nerve blocks with the injection of local anesthetic (bupivacaine $0.25 \%$ ) whereas, Group II patients received lumbar facet joint nerve blocks with a mixture of bupivacaine and betamethasone. Both groups were also divided into an additional category in each group with the addition of Sarapin. Thus, Group I, category A patients received lumbar facet joint nerve blocks with injections of $0.25 \%$ bupivacaine, whereas Group I, category B patients received lumbar facet joint nerve blocks with a mixture of $0.25 \%$ bupivacaine and Sarapin. Similarly, Group II, category A received lumbar facet joint nerve blocks with a mixture of $0.25 \%$ bupivacaine and betamethasone, whereas category B patients in Group II received lumbar facet joint nerve blocks with a mixture of $0.25 \%$ bupivacaine, Sarapin, and betamethasone. All mixtures consisted of clear solutions. Sarapin and bupivacaine were mixed in equal volumes, and $0.15 \mathrm{mg}$ of non-particulate betamethasone was added per milliliter of solution for Group II.

\section{Interventions}

All patients were provided with IRB-approved protocol and the informed consent which described in detail all aspects of the study and withdrawal process.

\section{Pre-enrollment Evaluation}

The pre-enrollment evaluation included the diagnosis of facet joint pain by controlled comparative local anesthetic blocks. Additional information included demographic data, medical and surgical history with 
co-existing disease(s), radiologic investigations, physical examination, pain rating scores using the Numeric Rating Scale (NRS), work status, opioid intake, and functional status assessment by Oswestry Disability Index.

All the patients were evaluated and included for the study with controlled facet joint nerve blocks for lumbar facet joint pain based on historical, clinical, and radiological evaluations. Only patients with nonspecific low back pain with a duration of at least 6 months were included. Patients with disc-related pain with or without radicular symptoms were excluded based on negative radiologic testing and negative or non-focal neurologic evaluation.

\section{Inclusion Criteria}

Inclusion criteria were a diagnosis of lumbar facet joint pain by means of controlled comparative local anesthetic blocks; patients who were 18 years of age; patients with a history of chronic function-limiting low back pain of at least 6 months duration; and patients who are competent to understand the study protocol and provide voluntary, written informed consent and participate in outcome measurements.

Inclusion criteria also included that there was no evidence of disc-related pain and patients also have undergone and failed to improve substantially with conservative management including but not limited to physical therapy, chiropractic manipulation, exercises, drug therapy, and bedrest.

\section{Exclusion Criteria}

Exclusion criteria were lack of positive response to controlled comparative local anesthetic blocks, uncontrollable or unstable opioid use, uncontrolled psychiatric disorders, uncontrolled medical illness either acute or chronic, any conditions that could interfere with the interpretation of the outcome assessments, positioning, women who are pregnant or lactating, and patients with a history or potential for adverse reaction(s) to local anesthetic, Sarapin, or steroid.

Lumbar Facet Joint Nerve Blocks

All facet joint nerve blocks were performed in a sterile operating room in an ambulatory surgery center, under fluoroscopy. Controlled comparative facet joint nerve blocks were performed in all the patients. The diagnostic process started with diagnostic facet joint nerve blocks using $0.5 \mathrm{~mL}$ of $1 \%$ lidocaine. Patients with lidocaine-positive results were studied using $0.5 \mathrm{~mL}$ of $0.25 \%$ bupivacaine on separate occasions, usually $3-4$ weeks after the first injection. Target joints were identified by the pain pattern, local or paramedian tenderness over the area of the facet joints, and reproduction of pain with deep pressure. Medial branch blocks were performed from L1 to L4 levels and $L 5$ dorsal ramus based on the clinical evaluation. Mild sedation with Midazolam was provided. A positive response was defined as at least $80 \%$ reduction of pain assessed by a numeric pain rating score (NRS) and the ability to perform previously painful movements with continued $80 \%$ relief. A response was considered positive, if pain relief lasted at least 2 hours following the lidocaine injection and lasted at least 3 hours or greater than the duration of relief with lidocaine, when bupivacaine was used. All other responses were considered as negative.

Therapeutic facet joint nerve blocks were performed at the same levels as diagnostic facet joint nerve blocks which led to the inclusion into the study utilizing solutions as assigned. The facet joint nerve blocks were performed on the ipsilateral side in patients with unilateral pain, or bilateral in patients with bilateral or axial pain. The facet joint nerve blocks were performed on a minimum of 2 nerves to block a single joint. Each nerve was injected with 0.5 to $1.0 \mathrm{~mL}$ of the assigned mixture.

Repeat therapeutic facet joint nerve blocks were provided based on the response to prior therapeutic facet joint nerve blocks evaluated by improvement in physical and functional status. However, therapeutic facet joint nerve blocks were repeated only when increased levels of pain were reported with deteriorating relief of below $50 \%$.

Additional Interventions

All the patients underwent the treatments as assigned. A patient was unblinded on request or if an emergency situation existed. If a patient required additional facet joint nerve blocks, the blocks were provided based on the patient's response, either after unblinding or without unblinding. If the patient chose not to be unblinded, the prior treatment was repeated as assigned. However, if patients chose to be unblinded, they were offered either the assigned treatment or another treatment based on response. If the patients were non-responsive and different treatments other than lumbar facet joint nerve blocks were required, they were considered to be withdrawn from the study, and no subsequent data were collected. In addition, all patients who were lost to follow-up were considered withdrawn.

\section{Co-interventions}

Most patients were receiving opioids and nonopioid analgesics, adjuvant analgesics, and some were 
involved in a therapeutic exercise program. If patients were improving significantly and the medical necessity for these drugs was lacking, medications were stopped or dosages were decreased. Further, if required, dosages were also increased. However, patients continued previously directed exercise programs, as well as their work. In this study, there was no specific physical therapy, occupational therapy, bracing, or other interventions offered.

\section{Objective}

The study was designed to evaluate the effectiveness of therapeutic lumbar facet joint nerve blocks in managing chronic low back pain and to compare the role of Sarapin and steroid in providing effective and long-lasting pain relief.

\section{Outcomes}

Multiple outcome measures were utilized which included numeric rating scale (NRS), the Oswestry Disability Index 2.0 (ODI), employment status, and opioid intake, with assessment at 3 months, 6 months, and 12 months post-treatment. Numeric rating scale (NRS) represented 0 with no pain and 10 with the worst pain imaginable. Oswestry Disability Index 2.0 (ODI) was utilized for functional assessment. Value and validity of the ODI has been reported (38). Thresholds for the minimum clinical important difference for ODI varied from a 4 to 15 points change of a total score of 50 . Significant pain relief was described as $50 \%$ or more, whereas significant improvement in function was described as at least a $40 \%$ reduction of ODI.

Based on the dosage frequency and schedule of the drug, opioid intake was determined as none, mild, moderate, or heavy. Intake of scheduled drugs was rated from mild to heavy. Schedule IV opioids (i.e., propoxyphene, pentazocine, and tramadol up to a maximum of 4 times, or hydrocodone twice a day or less) was considered as mild; intake of Schedule III opioids (i.e., hydrocodone up to 4 times a day) was considered as moderate; and intake of Schedule II opioids (i.e., oxycodone, morphine, meperidine, methadone, and transdermal fentanyl, in any dosage) was considered to be heavy.

Employment and work status were determined based on employability rather than all the patients in the study. Those patients who were employed on a parttime basis due to pain were classified as employable. However, if the patient's status of not being employed was secondary to being a housewife with no desire to return to work, retired, or over the age 65 , they were all considered in the non-employable category.

\section{Sample Size}

A sample size of 60 patients was chosen for each group. The estimated sample size was based on previous studies of cervical (39) and lumbar medial branch neurotomies (35), which included less than 20 patients in each group, and other literature of interventional techniques identifying as 50 patients as acceptable (40).

\section{Randomization}

From a total of 120 patients, 60 patients were randomly assigned into each group, and 30 patients into each category for Sarapin.

Sequence Generation

Randomization was performed by computer-generated random allocations sequence in blocks of 20 patients.

\section{Allocation Concealment}

The operating room nurse assisting with the procedure, randomized the patients and prepared the drugs appropriately.

Implementation

Participants were invited to enroll in the study if they met inclusion criteria. One of the 3 nurses assigned as coordinators of the study enrolled the participants and assigned participants to their respective groups.

\section{Statistical Methods}

Statistical analysis included chi-squared statistic, Fisher's exact test, paired t-test, and one-way analysis of variance.

Chi-squared statistic was used to test the differences in proportions. Fisher's exact test was used wherever the expected value was less than 5 , a paired t-test was used to compare the pre- and post-treatment results of average pain scores and Oswestry Disability Index measurements at baseline versus 3 months, 6 months, and 12 months. For comparison of mean scores between groups t-test was performed.

Initially both categories in each group were analyzed by comparing them to each other. Subsequently, if there were no differences, the 2 groups were compared.

\section{Intent-to-treat-analysis}

An intent-to-treat-analysis was performed. Either the last follow-up data or initial data were utilized in the patients who dropped out of the study and no other data were available. 
Results

\section{Participant Flow}

Figure 1 illustrates the participant flow.

\section{Recruitment}

The recruitment period lasted from November 2003 to July 2006.

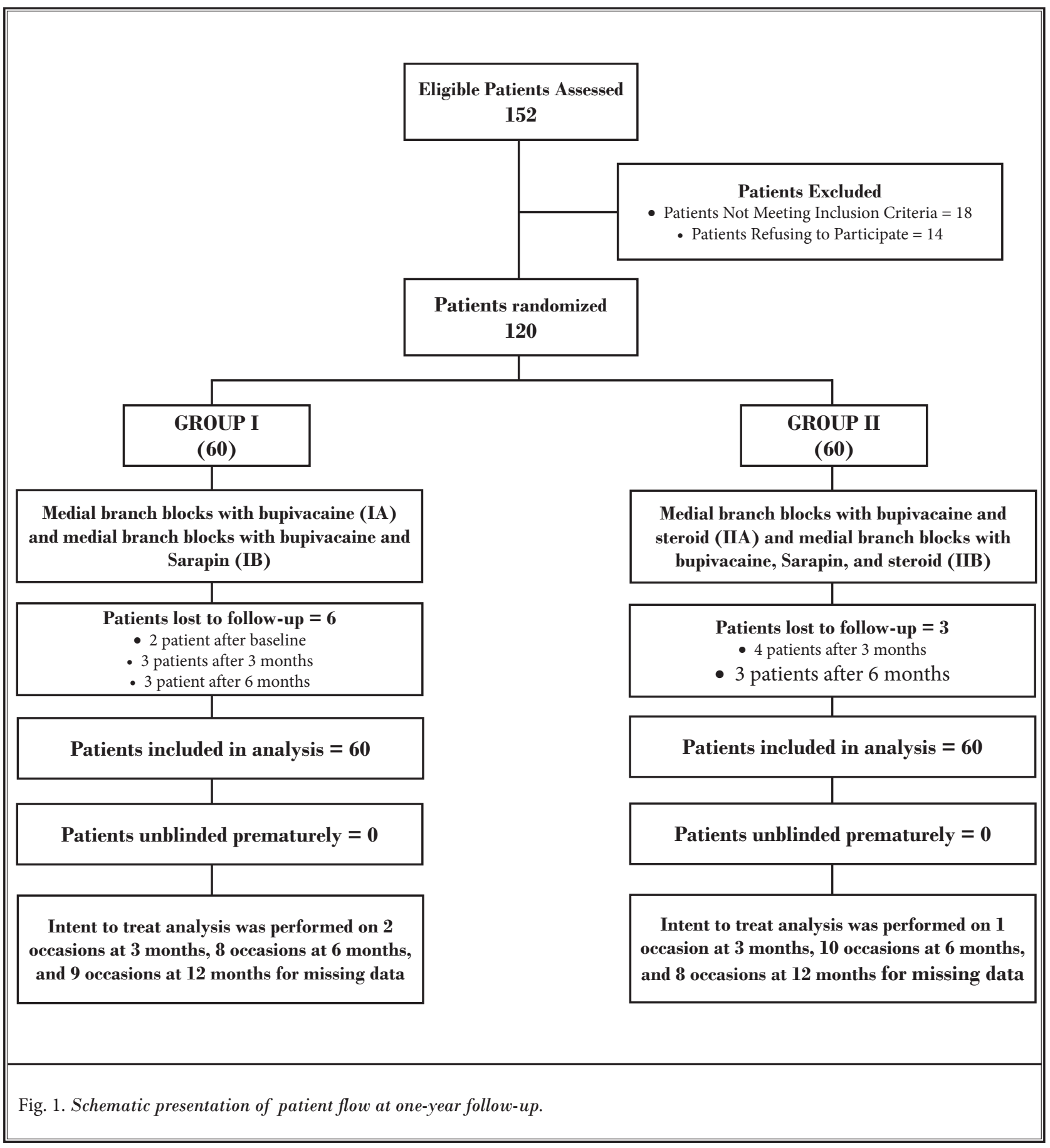


Table 1. Demographic characteristics.

\begin{tabular}{|l|c|c|c|}
\hline \multirow{2}{*}{} & & $\begin{array}{c}\text { Group I } \\
\text { (local anesthetic without steroid) } \\
(\mathbf{N = 6 0 )}\end{array}$ & $\begin{array}{c}\text { Group II } \\
\text { (local anesthetic with steroid) } \\
\text { (N = 60) }\end{array}$ \\
\hline \multirow{2}{*}{ Gender } & Male & $35 \%(21)$ & $45 \%(27)$ \\
\hline \multirow{2}{*}{ Age } & Female & $65 \%(39)$ & $55 \%(33)$ \\
\hline Height (inches) & Mean \pm SD & $48 \pm 15$ & $46 \pm 17$ \\
\hline Weight (lbs.) & Mean \pm SD & $66 \pm 3.8$ & $68^{*} \pm 4.1$ \\
\hline \multirow{2}{*}{$\begin{array}{l}\text { Duration of pain } \\
\text { (months) }\end{array}$} & Mean \pm SD & $183 \pm 48$ & $189 \pm 50$ \\
\hline \multirow{3}{*}{\begin{tabular}{l} 
Mode of onset of pain \\
\cline { 2 - 4 }
\end{tabular}} & Gradual & $108 \pm 102$ & $108 \pm 94$ \\
\cline { 2 - 4 } & Sudden & $52 \%(31)$ & $62 \%(37)$ \\
\hline
\end{tabular}

* indicates significant difference with Group I

$W C=$ Workers compensation

$\mathrm{MVA}=$ Motor vehicle injury

$\mathrm{N}=$ Number of patients

Table 2. Pain relief characteristics based on Numeric Rating Scale (NRS)

\begin{tabular}{|c|c|c|c|}
\hline & & $\begin{array}{c}\text { Group I } \\
\text { (local anesthetic without steroid) } \\
(\mathbf{N}=\mathbf{6 0})\end{array}$ & $\begin{array}{c}\text { Group II } \\
\text { (local anesthetic with steroid) } \\
(\mathrm{N}=60)\end{array}$ \\
\hline \multirow{4}{*}{$\begin{array}{l}\text { Average Pain Scores } \\
(\text { Mean } \pm \text { SD) }\end{array}$} & Baseline & $8.2 \pm 0.8$ & $7.9 \pm 1.0$ \\
\hline & 3 months & $3.8^{\star} \pm 1.3$ & $3.5^{\star} \pm 1.1$ \\
\hline & 6 months & $3.6^{*} \pm 1.5$ & $3.3^{\star} \pm 0.8$ \\
\hline & 12 months & $3.7^{\star} \pm 1.7$ & $3.5^{\star} \pm 1.1$ \\
\hline
\end{tabular}

* indicates significant difference with baseline values

$\mathrm{N}=$ Number of patients

\section{Baseline Data}

Demographic characteristics are illustrated in Table 1. There were no significant differences noted among the groups.

The number of joints involved was as follows: 2 joints were involved in $70 \%$ of the patients, whereas, 3 joints were involved in $30 \%$ of the patients. Bilateral involvement was seen in $79 \%$ of the patients.

\section{Analysis of Data}

Data were analyzed for both categories in each group to evaluate the influence of Sarapin. There were no significant differences. Thus, descriptions are provided for 2 groups with local anesthetic with or without steroid.

\section{Numbers Analyzed}

A schematic illustration of patient flow is provided in Fig. 1. The study period for 1-year follow-up lasted from November 2003 to July 2007 with completion of one-year follow-up for all the patients. The data were available in the majority of the patients. Intentto-treat-analysis was performed due to non-available data on 19 occasions in Group I and on 19 occasions in Group II, a total of 38 of 480 occasions with total data collection of 120 patients at baseline, 3 months, 6 months, and 12 months.

\section{Outcomes}

\section{Pain Relief}

Table 2 and Fig. 2 illustrate the numeric pain scale scores at baseline, 3 months, 6 months, and 12 months. 


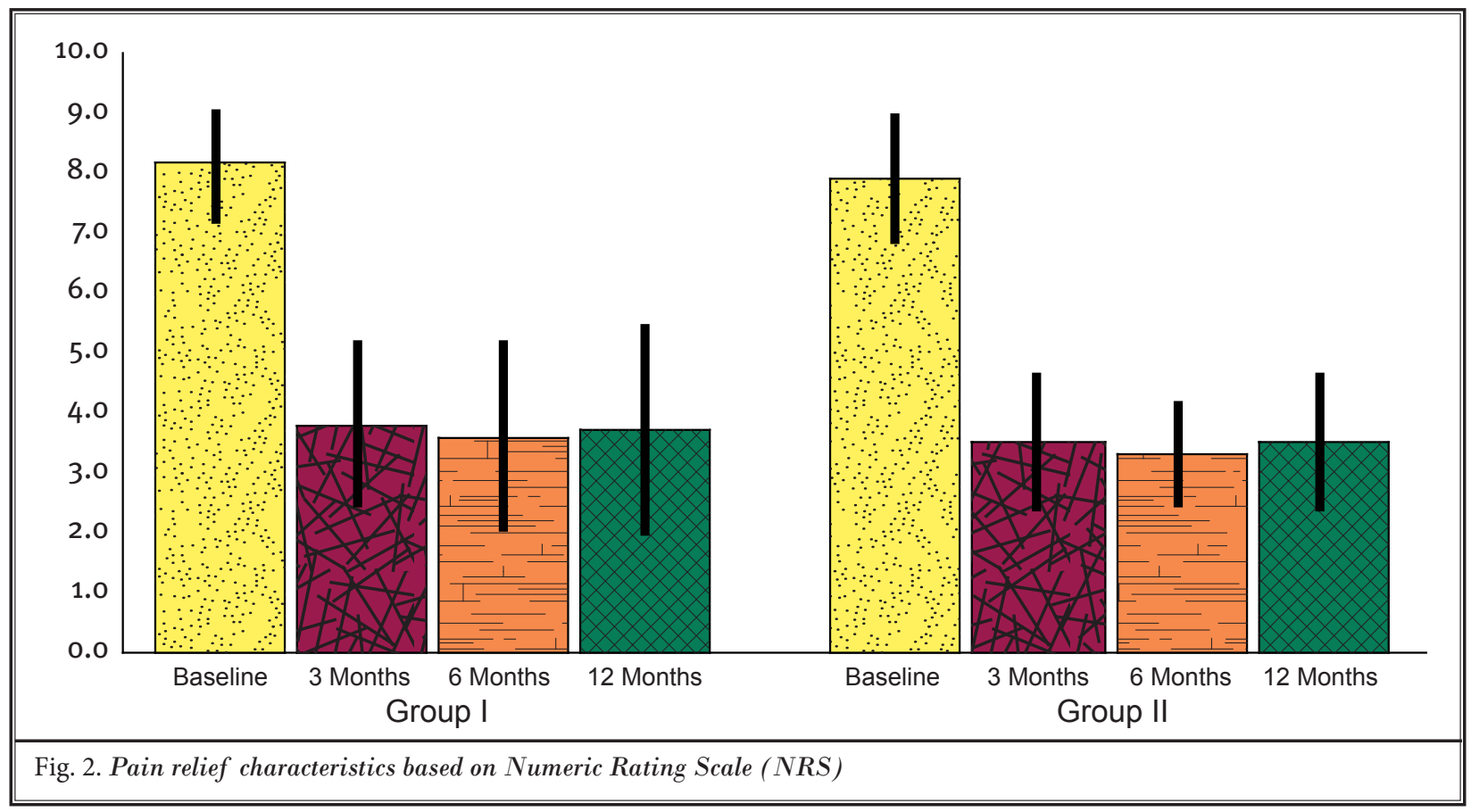

Table 3. Therapeutic procedural characteristics over a period of one year with average relief per procedure in weeks.

\begin{tabular}{|c|c|c|}
\hline Number of Procedures & $\begin{array}{c}\text { Group I } \\
\text { (local anesthetic without steroid) } \\
(\mathbf{N}=60)\end{array}$ & $\begin{array}{c}\text { Group II } \\
\text { (local anesthetic with steroid) } \\
(\mathrm{N}=60)\end{array}$ \\
\hline One & $\begin{array}{c}25 \pm 23.3 \\
(8)\end{array}$ & $\begin{array}{c}37 \pm 20.6 \\
(5)\end{array}$ \\
\hline Two & $\begin{array}{c}20 \pm 10.5 \\
(6)\end{array}$ & $\begin{array}{c}14 \pm 8.3 \\
\quad(8)\end{array}$ \\
\hline Three & $\begin{array}{c}14 \pm 4.3 \\
(8)\end{array}$ & $\begin{array}{c}15 \pm 2.2 \\
(13)\end{array}$ \\
\hline Four & $\begin{array}{c}12 \pm 1.1 \\
(31)\end{array}$ & $\begin{array}{c}12 \pm 1.1 \\
(31) \\
\end{array}$ \\
\hline Five & $\begin{array}{c}10 \pm 0.4 \\
(7)\end{array}$ & $\begin{array}{c}10 \pm 0.2 \\
(3)\end{array}$ \\
\hline Average relief per procedure & $\begin{array}{c}15 \pm 9.9 \\
(60)\end{array}$ & $\begin{array}{c}15 \pm 9.2 \\
(60)\end{array}$ \\
\hline
\end{tabular}

Mean \pm SD

$\mathrm{N}=$ Number of patients

Pain scores changed significantly from baseline, at 3 months, 6 months, and 12 months in all groups, with no significant differences among the groups or follow-up periods.

The proportion of patients with significant pain relief of $50 \%$ or greater is illustrated in Fig. 3. At 3 months, 6 months, and 12 months, $82 \%$ to $93 \%$ of the patients obtained significant pain relief with no significant differences among the groups, or from the 6-month and 12-month outcomes.
Therapeutic procedural characteristics with average pain relief per procedure are illustrated in Table 3. Average relief per procedure ranged from $15 \pm 9.9$ weeks in Group I and $15 \pm 9.2$ weeks in Group II.

Therapeutic procedural characteristics with average total relief over a period of 1 year are illustrated in Table 4 with an average total pain relief of 44 or 45 weeks over a period of one year.

Functional Assessment

Functional assessment results assessed by Oswes- 
Table 4. Therapeutic procedural characteristics with average total relief in weeks over a period of one year.

\begin{tabular}{|l|c|c||}
\hline \hline Number of Procedures & $\begin{array}{c}\text { Group I } \\
\text { (local anesthetic without steroid) } \\
(\mathbf{N}=\mathbf{6 0})\end{array}$ & $\begin{array}{c}\text { Group II } \\
\text { (local anesthetic with steroid) } \\
\text { (N = 60) }\end{array}$ \\
\hline One & $25 \pm 23.3(8)$ & $37 \pm 20.6(5)$ \\
\hline Two & $39 \pm 21.0(6)$ & $28 \pm 16.5(8)$ \\
\hline Three & $43 \pm 12.9(8)$ & $46 \pm 6.6(13)$ \\
\hline Four & $50 \pm 4.3(31)$ & $49 \pm 4.6(31)$ \\
\hline Five & $51 \pm 2.3(7)$ & $51 \pm 1.2(3)$ \\
\hline Total (For 1 year) & $45 \pm 14.3(60)$ & $44 \pm 11.6(60)$ \\
\hline
\end{tabular}

Mean \pm SD

$\mathrm{N}=$ Number of patients

Table 5. Functional assessment evaluated by Oswestry Disability Index.

\begin{tabular}{||l|c|c||}
\hline \hline & $\begin{array}{c}\text { Group I } \\
\text { (local anesthetic without steroid) } \\
(\mathbf{N}=\mathbf{6 0})\end{array}$ & $\begin{array}{c}\text { Group II } \\
\text { (local anesthetic with steroid) } \\
(\mathbf{N}=\mathbf{6 0})\end{array}$ \\
\hline Baseline & $26.6 \pm 4.6$ & $25.9 \pm 5.0$ \\
\hline 3 months & $12.7^{*} \pm 4.7$ & $13.5^{*} \pm 5.6$ \\
\hline 6 months & $12.7^{*} \pm 4.7$ & $12.2^{\star} \pm 5.0$ \\
\hline 12 months & $12.3^{*} \pm 4.8$ & $12.0^{*} \pm 5.4$ \\
\hline
\end{tabular}

Mean \pm SD

* indicates significant difference with baseline values

$\mathrm{N}=$ Number of patients

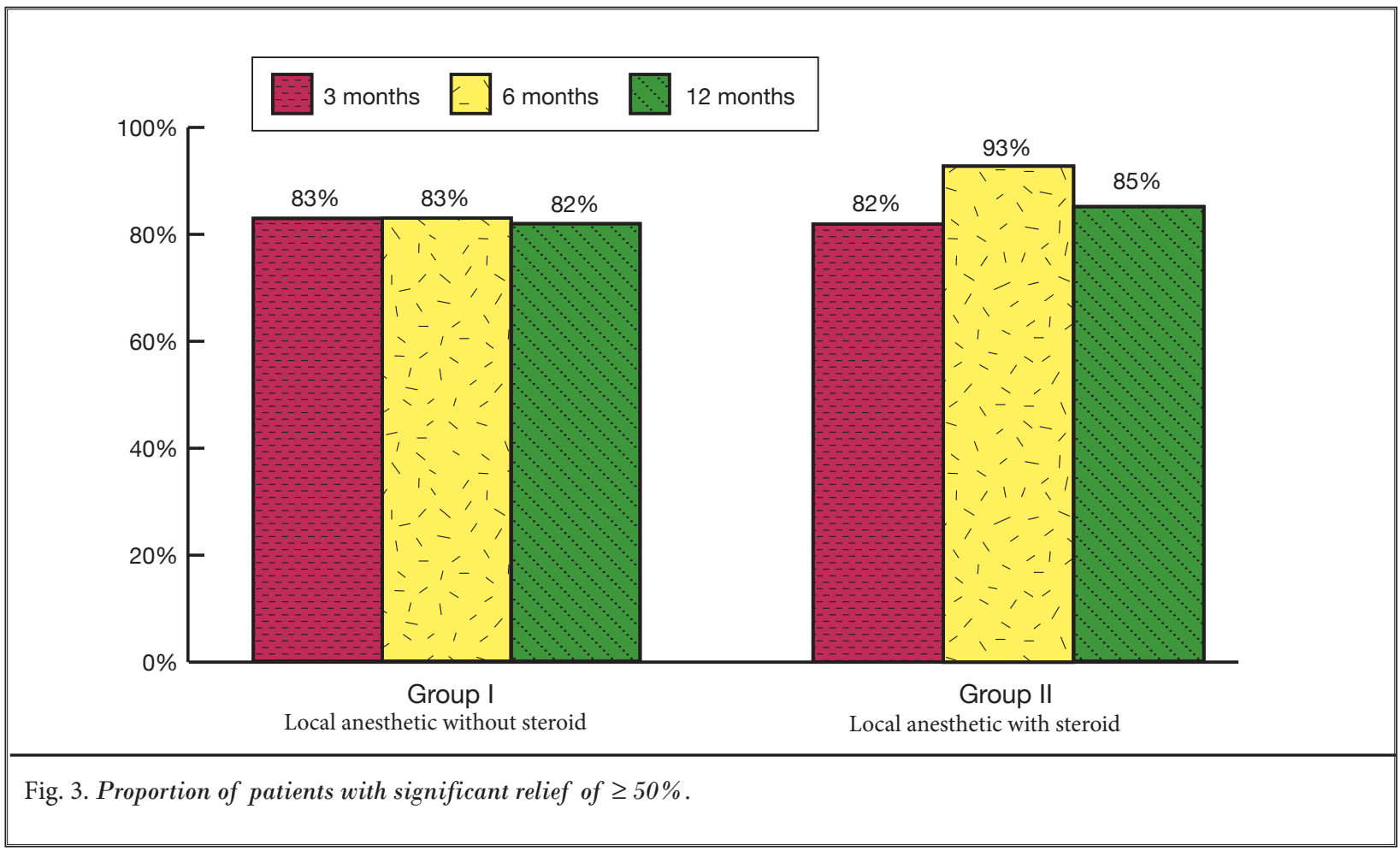


Table 6. Employment characteristics.

\begin{tabular}{|c|c|c|c|c|}
\hline \multirow[t]{2}{*}{ Employment Status } & \multicolumn{2}{|c|}{$\begin{array}{c}\text { Group I } \\
\text { (local anesthetic without steroid) } \\
(\mathbf{N}=\mathbf{6 0})\end{array}$} & \multicolumn{2}{|c|}{$\begin{array}{c}\text { Group II } \\
\text { (local anesthetic with steroid) } \\
(\mathrm{N}=60)\end{array}$} \\
\hline & Baseline & 12 months & Baseline & 12 months \\
\hline Employed part-time & 4 & 4 & 4 & 2 \\
\hline Employed full-time & 6 & 12 & 13 & 20 \\
\hline Total employed & 10 & 16 & 17 & 22 \\
\hline Unemployed - due to strike & 0 & 0 & 2 & 0 \\
\hline Unemployed due to pain & 6 & 1 & 4 & 3 \\
\hline Total unemployed & 6 & 1 & 6 & 3 \\
\hline Housewife & 7 & 4 & 3 & 2 \\
\hline Disabled & 29 & 30 & 25 & 24 \\
\hline Over 65 year of age & 8 & 9 & 9 & 9 \\
\hline Total not working & 44 & 43 & 37 & 35 \\
\hline Total number of patients & 60 & 60 & 60 & 60 \\
\hline
\end{tabular}

$\mathrm{N}=$ Number of patients

try Disability Index are illustrated in Table 5. Significant improvement was seen in the functional status in both groups from baseline to one year. Reduction of Oswestry scores of at least $40 \%$ was seen in $85 \%$ of the patients in Group I and $78 \%$ in Group II, whereas, a $50 \%$ reduction was seen in $70 \%$ of the patients in Group I and 65\% in Group II.

Employment Characteristics

Table 6 demonstrates employment characteristics in both groups. At baseline, there were 16 patients employable in Group I and of these, 10 were employed and 6 were unemployed, whereas in Group II, there were 23 employable and 17 were employed at baseline.

At one-year follow-up, there were 16 employed in Group I and 22 employed in Group II.

Opioid Intake

The majority of the patients at baseline, as well as at 12 months, received moderate doses of opioids, with no significant differences noted between the non-steroid and steroid groups.

\section{Adverse Events}

There were no major adverse events reported over a period of one year.

\section{Discussion}

This study of 120 patients showed significant pain relief in $82 \%$ to $93 \%$ of the patients with no significant differences noted with or without steroid over a period of one year. In addition, functional assessment measured by Oswestry Disability Index also showed significant improvement with at least a $40 \%$ reduction in $85 \%$ of the patients in Group I and $78 \%$ of the patients in Group II, whereas, at least a $50 \%$ reduction was seen in $70 \%$ of the patients in Group I and $65 \%$ of the patients in Group II. The average procedures per year were 3.3 and 3.4 with an average relief per year of approximately 15 weeks per procedure and patients experiencing approximately 44 or 45 weeks of relief during the period of 52 weeks with repeat blocks.

While the results of employment and opioid reduction are not significant, the pain relief and improvement in functional status are significant in this randomized, double-blind trial of patients with chronic function-limiting low back pain treated with therapeutic lumbar facet joint nerve blocks. Further, strict criteria have been utilized for diagnosis of facet joint pain by controlled comparative local anesthetic blocks, thus avoiding criticism of including patients without facet joint pain in the study.

The basis for intraarticular injections has been that there is inflammation and steroids are used to treat the inflammation. However, with lumbar facet joint nerve blocks, no such claims have been made either with the presence or reduction of inflammation with the blockade. The present study shows equal effectiveness of local anesthetics with or without steroid, indicating a lack of support for the proposition of inflammation. It has been described that steroids exert their effectiveness by anti-inflammatory, immuno-suppressive, anti-edema effects, and inhibition of neurotransmis- 
sion within the $C$ fibers (41-44). In contrast, the local anesthetics have been shown to provide short-term as well as intermediate term symptomatic relief, even though the mechanism of action providing such relief is not known. However, local anesthetics are different from steroids as local anesthetics are also effective in neuropathic pain where steroids have very little effect (45). Further, it also has been postulated that local anesthetics provide the relief by multiple mechanisms which include suppression of nociceptive discharge (46), the blockade of sympathetic reflex arc $(42,47)$, the blockade of axonal transport $(48,49)$, the blockade of sensitization $(50,51)$, and anti-inflammatory effects (52). In addition, local anesthetics have been shown to block the axonal transport of the nerve fibers with lower concentrations of local anesthetics compared with those which are necessary for a block of nerve conduction $(48,49)$. Further, multiple previous studies also have shown prolonged relief following local anesthetic nerve block or epidural injections $(5,46,53,54)$. In fact, as early as 1941, Wertheim and Rovenstine (54) reported that the analgesic effect of a $2 \%$ procaine injection may continue for 4 to 6 weeks. In 1990, Arner et al (46) reported the long lasting effectiveness of local anesthetic conduction blocks beyond the expected duration of local anesthetic with complete pain relief lasting 12 to 48 hours and further relief lasting 4 to 6 days. This phenomenon of pain relief beyond the local anesthetic effect has been reported after a single block, as well as a series of blocks over the years (5561). Consequently, it is postulated that the effectiveness of local anesthetics is based on the direct effects of local anesthetic on various mechanisms in chronic pain including noxious peripheral stimulation, sensitization $(50,51)$, neurotransmitter release resulting in secondary hyperalgesia (62), and phenotype changes, which form the basis for neuronal plasticity $(63,64)$. These mechanisms of chronic pain are similar to the mechanisms described in neuropathic pain (63-65). Based on the same mechanism, it is presumed that local anesthetics are effective in the prevention of onset and treatment of phantom-limb syndrome $(51,66,67)$.

The study may be criticized for the lack of a placebo group. Considering the difficulties related to placebo groups in interventional techniques in the United States, the present study with local anesthetics with or without steroid is appropriate. In addition, in the modern medicine in evaluation of interventions, pragmatic or practical clinical trials measuring the effectiveness are considered more appropriate rather than explanatory trials measuring efficacy (68). Explanatory trials are most commonly conducted in academic settings measuring the efficacy, whereas pragmatic or practical trials are best designed to provide the results of benefit of the treatment produced in routine clinical practice. In addition, practical clinical trials address the questions about the risks, benefits, and costs of an intervention as they occur in routine clinical practice better than an explanatory trial in an academic setting (69). The issue of lack of a placebo group is addressed in pragmatic trials with the treatment response accounting for the total difference between 2 treatments, including both treatment as well as associated placebo effects. Consequently, the treatment response in a pragmatic trial is a combination of the treatment effect and placebo effect, as this will best reflect the likely clinical response in an actual clinical practice.

This study resolves the issues of the addition of Sarapin and steroid, even though conflicting results demonstrated the effect of Sarapin and steroid $(5,53)$. These results describe patients in a private practice interventional pain management setting in a practical and pragmatic clinical trial; consequently, the results are not applicable in the general population unless the same methodology is utilized with the diagnosis and therapy. Further, generalizability of the findings of this study may only be feasible in studies utilizing larger populations in multiple settings.

Overall, evidence in this report demonstrates lumbar facet joint pain diagnosed by controlled, comparative local anesthetic blocks with the criteria of $80 \%$ pain relief, which is sustained after prior painful movements for appropriate duration of action of local anesthetic, may be treated with lumbar medial branch blocks with or without steroid providing approximately 15 weeks of relief and requiring 3 to 4 episodes of treatment per year.

\section{Conclusion}

The results of this randomized, double-blind controlled evaluation of lumbar facet joint nerve blocks in chronic function-limiting low back pain demonstrate the effectiveness in over $82 \%$ of the patients with improvement in functional status.

\section{Acknowledgements}

The authors wish to thank Tonie Hatton and Diane Neihoff, transcriptionists, for their assistance in preparation of this manuscript; and the Pain Physician editorial board for their insights and suggestions. 


\section{References}

1. Manchukonda R, Manchikanti KN, Cash KA, Pampati V, Manchikanti L. Facet joint pain in chronic spinal pain: An evaluation of prevalence and false-positive rate of diagnostic blocks. I Spinal Disord Tech 2007; 20:539-545.

2. Manchikanti L, Boswell MV, Singh V, Pampati V, Damron KS, Beyer CD. Prevalence of facet joint pain in chronic spinal pain of cervical, thoracic, and lumbar regions. BMC Musculoskelet Disord 2004; 5:15.

3. Schwarzer AC, Aprill CN, Derby R, Fortin J, Kine G, Bogduk N. Clinical features of patients with pain stemming from the lumbar zygapophysial joints. Is the lumbar facet syndrome a clinical entity? Spine 1994; 19:1132-1137.

4. Schwarzer AC, Wang S, Bogduk N, McNaught PJ, Laurent R. Prevalence and clinical features of lumbar zygapophysial joint pain: A study in an Australian population with chronic low back pain. Am Rheum Dis 1995; 54:100-106.

5. Manchikanti L, Pampati VS, Fellows B, Bakhit CE. The diagnostic validity and therapeutic value of lumbar facet joint nerve blocks with or without adjuvant agents. Curr Rev Pain 2000; 4:337-344.

6. Manchikanti L, Pampati V, Fellows B, Bakhit CE. The inability of the clinical picture to characterize pain from facet joints. Pain Physician 2000; 3:158-166.

7. Manchikanti L, Singh V, Pampati VS, Damron KS, Barnhill RC, Beyer CD, Cash $\mathrm{KA}$. Evaluation of the relative contributions of various structures in chronic low back pain. Pain Physician 2001; 4:308-316.

8. Manchikanti L, Manchukonda R, Pampati V, Damron KS, McManus CD. Prevalence of facet joint pain in chronic low back pain in postsurgical patients by controlled comparative local anesthetic blocks. Arch Phys Med Rehabil 2007; 88:449-455.

9. Merskey H, Bogduk N. Classification of chronic pain. In: Merskey H, Bogduk N (eds). Descriptions of Chronic Pain Syndromes and Definition of Pain Terms. 2nd ed. IASP Press, Seattle, 1994, pp 180-181.

10. Bogduk N. Low back pain. In Bogduk's Clinical Anatomy of Lumbar Spine and Sacrum. 4th edition. Churchill Livingstone, New York, 2005, pp 183-216.

11. Kuslich SD, Ulstrom CL, Michael CJ. The tissue origin of low back pain and sciatica: A report of pain response to tis- sue stimulation during operation on the lumbar spine using local anesthesia. Orthop Clin North Am 1991; 22:181-187.

12. Bogduk N. International Spinal Injection Society guidelines for the performance of spinal injection procedures. Part 1: Zygapophyseal joint blocks. Clin J Pain 1997; 13:285-302.

13. Boswell MV, Singh V, Staats PS, Hirsch JA. Accuracy of precision diagnostic blocks in the diagnosis of chronic spinal pain of facet or zygapophysial joint origin. Pain Physician 2003; 6:449-456.

14. Seghal N, Dunbar EE, Shah RV, Colson JD. Systematic review of diagnostic utility of facet (zygapophysial) joint injections in chronic spinal pain: An update. Pain Physician 2007; 10:213-228.

15. Bogduk N, McGuirk B. Causes and sources of chronic low back pain. In: Bogduk N, McGuirk B (eds). Medical Management of Acute and Chronic Low Back Pain. An Evidence-Based Approach: Pain Research and Clinical Management. Vol. 13. Elsevier Science BV, Amsterdam, 2002, pp 115-126.

16. Mooney V, Robertson J. The facet syndrome. Clin Orthop 1976; 115:149-156.

17. McCall IW, Park WM, O’Brien JP. Induced pain referral from posterior elements in normal subjects. Spine 1979; 4:441446.

18. Marks R. Distribution of pain provoked from lumbar facet joints and related structures during diagnostic spinal infiltration. Pain 1989; 39:37-40.

19. Fukui S, Ohseto K, Shiotani M, Ohno K, Karasawa H, Naganuma Y. Distribution of referral pain from the lumbar zygapophysial joints and dorsal rami. Clin J Pain 1997; 13:303-307.

20. Windsor RE, King FJ, Roman SJ, Tata NS, Cone-Sullivan LA, Thampi S, Acebey M, Gilhool JJ, Rao R, Sugar R. Electrical stimulation induced lumbar medial branch referral patterns. Pain Physician 2002, 5:347-353.

21. Cavanaugh JM, Lu Y, Chen C, Kallakuri S. Pain generation in lumbar and cervical facet joints. J Bone Joint Surg Am 2006; 88:63-37.

22. Yang KH, King Al. Mechanism of facet load transmission as a hypothesis for low-back pain. Spine 1984; 9:557-565.

23. Mayer TG, Gatchel RJ, Keeley J, McGeary D, Dersh J, Anagnostis C. A randomized clinical trial of treatment for lumbar segmental rigidity. Spine 2004; 29:21992205.
24. Mayer T, Robinson R, Pegues P, Kohles $S$, Gatchel RJ. Lumbar segmental rigidity: Can its identification with facet injections and stretching exercises be useful? Arch Phys Med Rehabil 2000; 81:1143-1150.

25. Boswell MV, Trescot AM, Datta S, Schultz DM, Hansen HC, Abdi S, Sehgal N, Shah RV, Singh V, Benyamin RM, Patel VB, Buenaventura RM, Colson JD, Cordner HJ, Epter RS, Jasper JF, Dunbar EE, Atluri SL, Bowman RC, Deer TR, Swicegood JR, Staats PS, Smith HS, Burton AW, Kloth DS, Giordano J, Manchikanti L. Interventional techniques: Evidencebased practice guidelines in the management of chronic spinal pain. Pain Physician 2007; 10:7-111.

26. Boswell MV, Colson JD, Sehgal N, Dunbar EE, Epter R. A systematic review of therapeutic facet joint interventions in chronic spinal pain. Pain Physician 2007; 10:229-254.

27. Geurts JW, van Wijk RM, Stolker RJ, Groen GJ. Efficacy of radiofrequency procedures for the treatment of spinal pain: A systematic review of randomized clinical trials. Reg Anesth Pain Med 2001; 26:394-400.

28. Niemisto L, Kalso E, Malmivaara A, Seitsalo S, Hurri H; Cochrane Collaboration Back Review Group. Radiofrequency denervation for neck and back pain: A systematic review within the framework of the Cochrane Collaboration Back Review Group. Spine 2003; 28:1877-1888

29. Nelemans P, de Bie R, de Vet HC, Sturmans F. WITHDRAWN: Injection therapy for subacute and chronic benign lowback pain. Cochrane Database Syst Rev 2007; 3:CDoo1824.

30. Manchikanti L, Singh V, Vilims B, Hansen HC, Schultz DM, Kloth DS. Medial branch neurotomy in management of chronic spinal pain: Systematic review of the evidence. Pain Physician 2002; 5:405-418.

31. Carette S, Marcoux S, Truchon R, Grondin C, Gagnon J, Allard Y, Latulippe M. A controlled trial of corticosteroid injections into facet joints for chronic low back pain. $N$ Engl J Med 1991; 325:1002-1007.

32. Schulte TL, Pietila TA, Heidenreich J, Brock M, Stendel R. Injection therapy of lumbar facet syndrome: A prospective study. Acta Neurochir (Wien) 2006; 148:1165-1172. 
33. Manchikanti L, Manchikanti KN, Manchukonda R, Cash KA, Damron KS, Pampati V, McManus CD. Evaluation of lumbar facet joint nerve blocks in the management of chronic low back pain: A preliminary report of a randomized, double-blind controlled trial. Clinical Trial NCTo00355914. Pain Physician 2007; 10:425-440.

34. Manchikanti L, Manchikanti KN, Damron KS, Pampati V. Effectiveness of cervical medial branch blocks in chronic neck pain: A prospective outcome study. Pain Physician 2004; 7:195-202.

35. van Kleef $M$, Barendse GA, Kessels A, Voets HM, Weber WE, de Lange S. Randomized trial of radiofrequency lumbar facet denervation for chronic low back pain. Spine 1999; 24:1937-1942.

36. Dreyfuss P, Halbrook B, Pauza K, Joshi A, McLarty J, Bogduk N. Efficacy and validity of radiofrequency neurotomy for chronic lumbar zygapophysial joint pain. Spine 2000; 25:1270-1277.

37. Moher D, Schulz KF, Altman D, for the CONSORT Group. The CONSORT statement: revised recommendations for improving the quality of reports of parallel-group randomized trials. JAMA. 2001;285:1987-1991.

38. Fairbank JCT, Pynsent PB. The Oswestry disability index. Spine 2000; 25:29402953.

39. Lord SM, Barnsley L, Wallis BJ, McDonald GJ, Bogduk N. Percutaneous radiofrequency neurotomy for chronic cervical zygapophysial joint pain. $N$ Engl $)$ Med 1996; 335:1721-1726.

40. Koes BW, Scholten RJ, Mens JM, Bouter LM. Efficacy of epidural steroid injections for low-back pain and sciatica: A systematic review of randomized clinical trials. Pain 1995; 63:279-288.

41. Grenier B, Castagnera L, Maurette $P$, Erny P, Senegas J. Chronic cervico-brachial neuralgia treated by cervical epidural injection of corticosteroids. Longterm results. Ann Fr Anesth Reanim 1995; 14:484-488.

42. Hayashi N, Weinstein JN, Meller ST, Lee HM, Spratt KE, Gebhart GE. The effect of epidural injection of betamethasone or bupivacaine in a rat model of lumbar radiculopathy. Spine 1998; 23:877885.

43. Lee HM, Weinstein JN, Meller ST, Hayashi N, Spratt KF, Gebhart GF. The role of steroids and their effects on phospholipase A2. An animal model of radiculopathy. Spine 1998; 23:11911196.

44. Johansson A, Hao J, Sjolund B. Local corticosteroid application blocks transmission in normal nociceptive C-fibres. Acta Anaesthesiol Scand 1990; 34:335338.

45. Mao J, Chen LL. Systemic lidocaine for neuropathic pain relief Pain 2000; 87:7-17.

46. Arner S, Lindblom U, Meyerson BA, Molander $\mathrm{C}$. Prolonged relief of neuralgia after regional anesthetic block. A call for further experimental and systematic clinical studies. Pain 1990; 43:287297.

47. Benzon HT. Epidural steroid injections for low back pain and lumbosacral radiculopathy. Pain 1986; 24:277-295.

48. Lavoie PA, Khazen T, Filion PR. Mechanisms of the inhibition of fast axonal transport by local anesthetics. Neuropharmacol 1989; 28:175-181.

49. Bisby MA. Inhibition of axonal transport in nerves chronically treated with local anesthetics. Exp Neurol 1975; 47:481-489.

50. Katz WA, Rothenberg R. The nature of pain: Pathophysiology. J Clin Rheumatol 2005; 11(2 suppl):S11-15.

51. Melzack R, Coderre TJ, Katz J, Vaccarino AL. Central neuroplasticity and pathological pain. Ann N Y Acad Sci 2001; 933:157-174.

52. Cassuto J, Sinclair R, Bonderovic M. Anti-inflammatory properties of local anesthetics and their present and potential clinical implications. Acta Anaesthesiol Scand 2006; 50:265-282.

53. Manchikanti KN, Pampati V, Damron KS, McManus CD. A double-blind, controlled evaluation of the value of Sarapin in neural blockade. Pain Physician 2004; 7:59-62.

54. Wertheim HM, Rovenstine EA. Suprascapular nerve block. Anesthesiology 1941; 2:541.

55. Abram SE, Likavec MJ. Pain syndromes and rationale for management. Neurogenic pain. In: Raj P, (ed.) Practical Management of Pain. Year Book Medical Publishers, Chicago, 1986, pp 182191.

56. Bonica JJ. The Management of Pain. Lea and Febiger, Philadelphia, 1963.

57. Bonica JJ. Current role of nerve blocks in diagnosis and therapy of pain. In Bonica JJ (ed). Advances in Neurology,
Vol. 4. Raven Press, New York, 1974, pp 445-453.

58. Livingston WK. Pain Mechanisms. Macmillan, New York, 1943.

59. Raj PP. Prognostic and therapeutic local anaesthetic blockade. In Cousins MJ, Bridenbaugh PO, eds. Neural Blockade. Lippincott, Philadelphia, 1988, pp 900-901.

6o. Kibler RF, Nathan PW. Relief of pain and paraesthesiae by nerve block distal to a lesion. J Neurol Neurosurg Psychiat 1960; 23:91-98.

61. Xavier AV, McDanal J, Kissin I. Relief of sciatic radicular pain by sciatic nerve block. Anesth Analg 1988; 67:11771180

62. Pasqualucci A, Varrassi G, Braschi A, Peduto VA, Brunelli A, Marinangeli F, Gori F, Colo F, Paladini A, Mojoli F. Epidural local anesthetic plus corticosteroid for the treatment of cervical brachial radicular pain: Single injection verus continuous infusion. Clin J Pain 2007; 23:551-557.

63. Kawakami M, Weinstein JN, Chatani K, Spratt KF, Meller ST, Gebhart GF. Experimental lumbar radiculopathy. Behavioral and histologic changes in a model of radicular pain after spinal nerve root irritation with chromic gut ligatures in the rat. Spine 1994; 19:1795-1802.

64. Decosterd I, Woolf CJ. Spared nerve injury: An animal model of persistent peripheral neuropathic pain. Pain 2000; 87:149-158.

65. Ji RR, Woolf CJ. Neuronal plasticity and signal transduction in nociceptive neurons: Implications for the initiation and maintenance of pathological pain. $\mathrm{Neu}$ robiol Dis 2001; 8:1-10.

66. Pasqualucci A. Experimental and clinical studies about the preemptive analgesia with local anesthetics. Possible reasons of the failure. Minerva Anestesiol 1998; 64:445-457.

67. Ferrante FM, Paggioli J, Cherukuri S, Arthur GR. The analgesic response to intravenous lidocaine in the treatment of neuropathic pain. Anesth Analg 1996; 82:91-97.

68. Tunis SR, Stryer DB, Clancy CM. Practical clinical trials. Increasing the value of clinical research for decision making in clinical and health policy. JAMA 2003; 290:1624-1632.

69. Roland M, Torgerson DJ. What are pragmatic trials? BMJ 1998; 316:285. 